\title{
A survey of occupational cancer in the rubber and cablemaking industries: analysis of deaths occurring in 1972-74
}

\author{
A. J. FOX and P. F. COLLIER
}

Office of Population Censuses and Surveys, Medical Statistics Division, St Catherines House, Kingsway, and the Employment Medical Advisory Service, Health and Safety Executive, London

\begin{abstract}
Fox, A. J. and Collier, P. F. (1976). British Journal of Industrial Medicine, 33, 249-264. A survey of occupational cancer in the rubber and cablemaking industries: analysis of deaths occurring in 1972-74. The records of 40867 men employed for at least one year in the rubber and cablemaking industries have now been observed for eight years. This analysis compares the mortality pattern for 1972-74 with that previously reported for 1968-71. It indicates a significant excess of deaths due to cancer of the bladder throughout the industry including men who had not been exposed to acknowledged bladder carcinogens. This excess is in deaths occurring in 1973 and 1974 in the 45-64 and 65 years plus age groups. The two sectors of the industry where this excess is significant are footwear and footwear supplies except adhesives, and the tyre sector. The excess of all cancers taken together previously noted throughout the study population for 1968-71 is confirmed for 1972-74 as is the excess for lung cancers. The greater excess in the tyre sector is also confirmed, particularly in those men in the 55-64 year age group and those who entered the industry between 1950 and 1960 . While men employed in 1967 on moulding, press, autoclave, and pan curing, and workers in finished goods, stores, packaging, and despatch continue to have more lung cancer deaths than expected for 1972-74, the excess is no longer statistically significant. An excess of cancer of the stomach which was overlooked in 1968-71 is not confirmed in 1972-74 but is nevertheless high when the total period of study 1968-74 is considered. The limitations of the study are discussed with particular reference to extrapolating the results to the whole industry. We conclude that there is a higher rate of lung cancer in the tyre sector of the industry and that immediate investigations are required to test the hypothesis concerning the recent excess of bladder cancers. Attention should now be paid to the control of exposures to all potential hazards in the industry.
\end{abstract}

Although bladder cancer as an occupational hazard of magneto workers was first reported in 1895 the causal agents were at that time wrongly identified, and the rapid growth of the synthetic dyestuff industry gave rise to an ever-increasing number of cases. Because of the long latent period, with a wide range between starting hazardous work and developing the disease (five to 50 years with an average of about 26 years), a back-log of cases is still appearing.

After a large-scale investigation into the hazard of bladder cancer in the production of synthetic dyes in the United Kingdom was set up in 1948, epidemiological evidence of a similar hazard in the British rubber industry was communicated to that industry in 1949 (Case and Hosker, 1954; Case, McDonald, and Pearson, 1954). Because it was by then fairly certain that 1- (alpha-) and 2- (beta-) naphthylamine, at least in their commercially available forms, were playing a major role in causing bladder cancer in the chemical 
and dyestuff industries, the chemical industry which manufactured them withdrew certain rubber additives from its sales range because they were made from one or both of the naphthylamines and contained sufficient uncharged naphthylamine as an impurity to be measurable by the analytical techniques then available. Both the rubber and the cablemaking industries were advised of this step, and were warned to return or destroy their stocks of the additives concerned.

In 1953 papilloma of the bladder in certain occupations was prescribed for benefit under the Industrial Injuries Act (Minister of Pensions and National Insurance, 1953), and in 1967 the Carcinogenic Substances Act (Minister of Labour, 1967) brought these chemicals under strict control. This action, however, gave no assurance that all potential urinary tract carcinogens had been identified and/or removed from use, or that the substitutes which replaced the discontinued additives were not themselves urinary tract carcinogens. In 1965 the Senior Medical Inspector of Factories' Advisory Panel on Occupational Cancer gave approval for a mortality study of the rubber and cablemaking industries to compare the pattern of mortality in three exposure groups. These were men employed in:

-(A) factories which had used known bladder carcinogens, and who entered these factories before 1 January 1950

-(B) factories which had used known bladder carcinogens, but who entered these factories after 31 December 1949

-(C) factories which had never used the known bladder carcinogens.

This study was set up to assess primarily if there was any evidence that a hazard of urinary tract cancer persisted, or had been reintroduced after the particular rubber additives which had fallen under suspicion had been withdrawn from use in the rubber and cablemaking industries; and whether there was any evidence of an occupational cancer hazard affecting sites other than the urinary tract, as had been suggested by studies carried out in other countries.

Fox, Lindars, and Owen (1974) described the mortality for 1967-71 of the 40867 men included in this study; a total of 2271 deaths were observed during this period. The main conclusion of the analysis of these deaths was that, although there was no indication that there were more deaths certified as being due to bladder cancer in persons not exposed to the recognized bladder carcinogens, there was an overall increase in cancer rates. This increase was associated with a lung cancer excess in the tyre sector of the industry and in the belting, hose, rubber with asbestos, and flooring sector. The current report is based on the analysis of the certified causes of a further 1992 deaths which occurred during the period 1972-74.

\section{Method}

A total of 40867 men employed in the rubber and cablemaking industry on 1 February 1967 were identified; details of these men were sent to the Office of Population Censuses and Surveys (OPCS) for England and Wales and to the Registrar General for Scotland so that we could subsequently be notified of deaths. Details of the study design are given by Fox et al. (1974).

Statistical comparisons are made between observed and expected deaths. Expected deaths are calculated for five-year age groups using the England and Wales death rates published annually by the Registrar General (1967-73). Although Scottish rates have not been calculated, these would have had only a marginal effect on expected values and none on the conclusions drawn. The expected deaths for 1974 are based on the 1973 death rates applied to the 1974 man years at risk. In Table 4 expected deaths are not age-standardized but are based simply on the whole industry, expected deaths being apportioned to each sector of the industry on the basis of the proportion of the total industry employed in each sector on 1 February 1967. For example, there were 4060.2 deaths in 1968-74 expected for the whole industry, 16035 men employed in the tyre sector and 40867 totally employed. The non-age-standardized expected number of deaths in the tyre sector is:

$\frac{4060.2 \times 16035}{40867}=1593.1$.

This approach is more accurate than may at first appear because the population studied covers men who were aged 35-64 years in 1967. The age distributions therefore showed relatively little variation between the sectors of the industry and the variations that did occur had only marginal effects on the mortality rates. The approach is used in Table 4 in order to identify the sectors of the industry meriting further study. All the excesses so highlighted were subsequently checked by calculating age-standardized expected rates. In all other tables age-standardized expected values are calculated.

Comparisons between observed and expected values are based on the assumption of a Poisson distribution and on the normal (gaussian) approximation to the Poisson where more than 15.0 deaths are expected. Twotailed tests have been used and the $5 \%$ level of significance has been adopted. Higher levels are indicated where they occur.

Discrepancies can be noted between some of these tables and those in the previous report. A recent check by the OPCS revealed that some deaths had not been recorded due to administrative arrangements; these will primarily affect the observed deaths and will also have a very minor impact on the expected deaths. This analysis uses published death rates for 1971 which differ slightly from the preliminary rates previously used. None of these differences results in differences in interpretation for 1968-71.

All death certificates were coded by the OPCS in accordance with the eighth revision of the International Classification of Diseases (World Health Organization, 1967). 


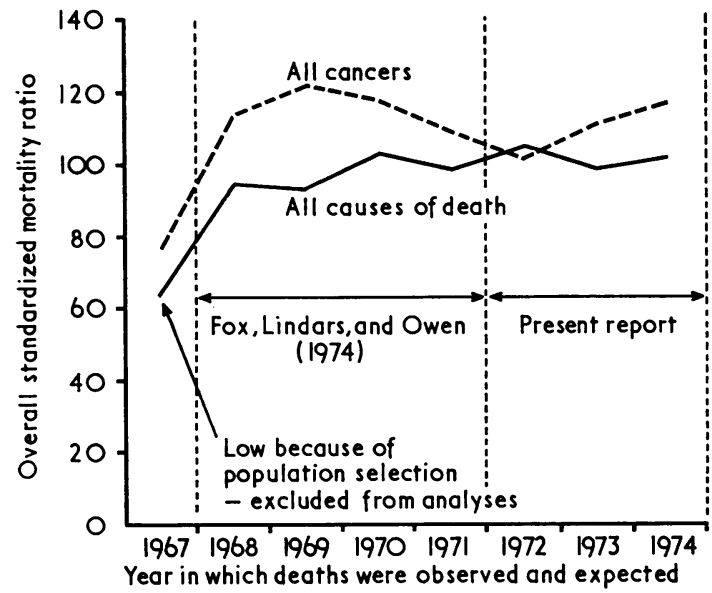

FIGURE Standardized mortality ratios for all deaths and all cancers according to year of death.

\section{Results}

Total population studied

The Figure shows the annual standardized mortality ratios (SMRs) for all deaths for 1967 to 1974 for the total population studied. The initially low value of
64 for all causes of death in 1967 has been attributed to the manner in which the sample was selected and the data for this year were therefore excluded from the analysis. The annual SMR for all deaths has remained constant at about $100 \%$ since 1970 . The Figure also shows the corresponding SMRs for all cancers. These were approximately $15 \%$ higher than those for all deaths in every year except 1972 when both were approximately 104 . The SMR for all cancers was 78 for 1967.

The observed and expected deaths and the SMRs according to certified cause are given for the total study population in Table 1 , in which the mortality pattern for 1968-71 is compared with that for 197274. The SMR for all cancers, although reduced from 116.3 in $1968-71$ to 110.6 in $1972-74$, is significantly high for both periods. The excess in 1968-71 was significant only in those subjects who after 1949 entered firms which had used acknowledged carcinogens (exposure group B). This excess is confirmed in 1972-74 (242 observed, $202 \cdot 3$ expected, $\mathbf{P}<0.01$ ) but there was in addition an excess in persons who entered these firms before the use of these chemicals ceased ( 242 observed, $214 \cdot 1$ expected, $P<0.05$ ).

A wider range of certified causes has been analysed than in the earlier report. Table 1 shows that for

TABLE 1

Observed and Expected Deaths for the Total Study Population According to CerTIFIED CAUSE FOR 1968-71 AND 1972-74

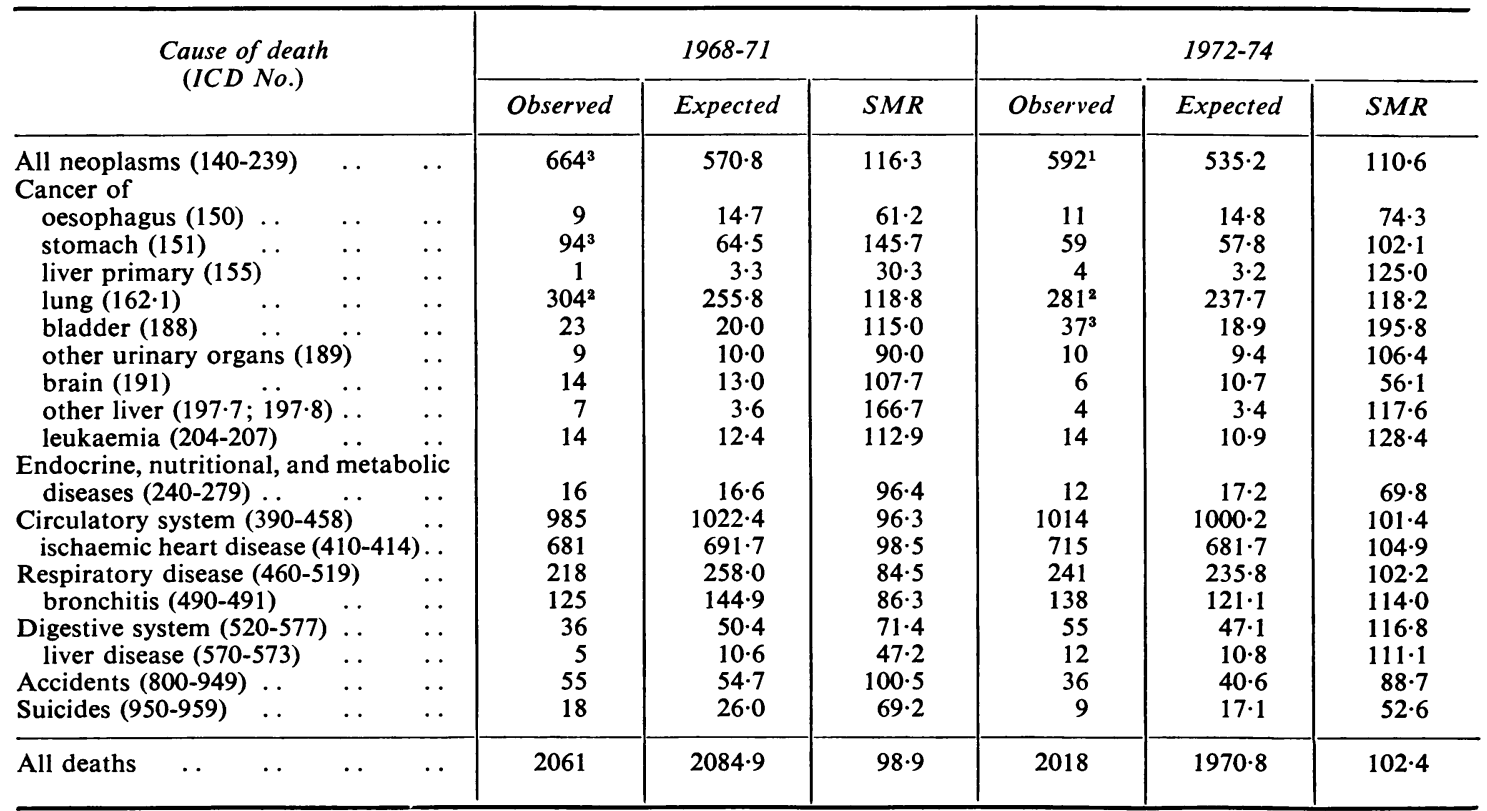

${ }^{1} \mathbf{P}<0.05$.

${ }^{2} \mathbf{P}<0.01$.

$3 \mathbf{P}<0.001$. 
1968-71 there was a significant excess of stomach cancers (94 observed, 64.5 expected, $P<0.001$ ) which was not previously identified. This excess is not evident in 1972-74 (59 observed, 57.8 expected, $P>0.05$ ). The significant excess of lung cancers reported for 1968-71 is confirmed for 1972-74 (281 observed, 237.7 expected, $P<0.01$ ). Although the SMR for all cancers is reduced from 116.3 to 110.6, the SMR for lung cancers remains approximately 118 for $1968-71$ and 1972-74.

For 1968-71 the observed number of 23 bladder cancers was not significantly in excess of the 20.0 expected. The number observed in 1972-74 (37) is however significantly more than that expected (18.9, $\mathrm{P}<0.001)$.

The SMR for respiratory disease has risen from 85 in 1968-71 to 102 in 1972-74 and that for diseases of the digestive system from 71 to 117 . This rise in diseases of the digestive system is associated with a rise in non-neoplastic liver disease which is also associated with one in primary liver cancer. These rises are statistically significant $(\mathbf{P}<0.05)$.

Carcinoma of the bladder (ICD 188.0-188.9)

The observed and expected number of deaths certified as due to bladder cancer and the SMRs are given in Table 2 for each year according to the exposure or possible exposure to the acknowledged bladder carcinogens used in the industry before 1950. Although for 1968 there was a significant excess in exposure group A (5 observed, 1.81 expected, $P<0.05$ ), persons who were employed in firms using carcinogenic compounds who entered those firms before 1950, there was no excess for the total population for any of the years 1967-71. In 1972 the excess in group A was repeated (6 observed, 2.45 expected, $P<0.05$ ) and in 1973 and 1974 excesses were also observed in the other two exposure groups. These were reflected in significant excesses for the total population studied (14 observed, 6.22 expected, $P<0.01$, for 1973; and 15 observed, 6.78 expected, $P<0.01$, for 1974).

In Table 3 the observed and expected certified bladder cancers are compared by age group as well as exposure group. The deaths are given for 1968-71 and 1972-74 separately. For the former period none of the excesses is significant but for the 1972-74 period several excesses are significant. In group A 16 certified bladder cancers were observed whereas only 7.8 were expected $(P<0.01)$. The major excess is in the 45-64 year age group where eight bladder cancers were observed and 3.5 were expected $(P<0.05)$. The excess in group $B$, that is, those persons who entered after 1950 those firms which, prior to their being prohibited used the acknowledged carcinogens, is not in a specific age group but in both the 45-64 and the 65 year plus age groups. Overall it is significant (13 observed, 6.9 expected, $P<0.05$ ). Although none of the excesses in exposure group $\mathbf{C}$ (persons employed in firms which never used the acknowledged carcinogens) is significant the SMRs are of the same order as for the other two exposure groups. Table 3 also shows that the excess observed in the overall population studied occurred in both the 45-64-year age group, with 20 observed and 9.5 expected $(P<0.01)$, and the 65 plus age group, with 17 observed and 9.2 expected $(P<0.05)$.

TABLE 2

Number of Observed and Expected Bladder Cancer Deaths and Standardized Mortality Ratios Each Year ACCORDing to ExPOSURE Group

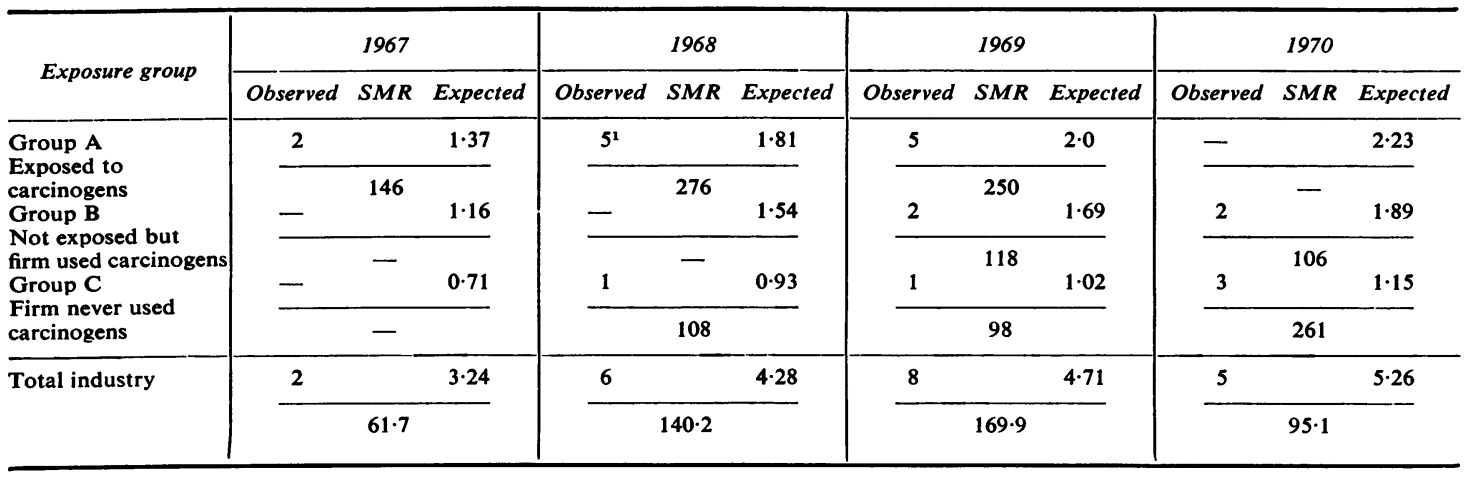

${ }^{1} P<0.05$.

$2 \mathbf{P}<0.01$. 
A crude approach has been adopted in Table 4 to identify sectors of the industry meriting detailed study because excess deaths have been observed. All deaths occurring between 1968 and 1974 are studied according to certified cause. Three industrial groups are found to have apparently significant excesses of bladder cancers. These are workers with cables and electrical goods (6 observed, $2 \cdot 4$ expected, $\mathbf{P}<0.05$ ); footwear and footwear supplies except adhesives ( 9 observed, 2.8 expected, $P<0.01)$; and surgical and medical goods, and gloves ( 4 observed, 0.6 expected, $P<0.01$ ). Although eight of these cases were in exposure group A, five were in exposure group B, and six in exposure group C. Table 4 also shows that there were 20 bladder cancers in the tyre sector, compared with $15 \cdot 3$ expected. For 1968-71, seven were observed compared with eight expected (Fox et al., 1974, Table 5). This suggests a significant excess of bladder cancers in the tyre sector for the period 197274.

\section{Mortality pattern by industry group}

Results for 1968-74 have been combined in Table 4 to provide more powerful tests for the smaller sectors of the industry than would have been available from independent analyses of 1968-71 and 1972-74. The excesses highlighted in this analysis will not be interpreted individually but will be checked by detailed age-standardized comparisons in subsequent tables. This analysis is performed as an indicator of sectors meriting closer study.

In the tyre sector there is an excess of all neo- plasms (519 observed, 434.0 expected, $\mathrm{P}<0.001$ ) which would appear to be associated with an excess of lung cancers (248 observed, 193.6 expected, $P<0.001)$ and an excess of cancers of the stomach (65 observed, 48.0 expected, $P<0.05$ ).

In belting, hose rubber with asbestos, and flooring there is a marked excess of all deaths (488 observed, 431.7 expected, $P<0.01)$ reflected in excesses in all cancers (140 observed, 117.7 expected, $P<0.05$ ), diseases of the circulatory system (248 observed, 215.3 expected, $P<0.05)$ and bronchitis (39 observed, 28.3 expected, $P<0.05$ ). The excess in all cancers is largely because of more lung cancers (71 observed, 52.5 expected, $\mathrm{P}<0.05$ ).

The tyre sector

Table 5 gives the observed and age standardized expected deaths in 1968-71 and 1972-74 by cause of death for the tyre sector. For 1968-71 a significant excess of all cancers was observed (273 observed, 217.2 expected, $P<0.001$ ). This includes a significant excess of stomach cancers (40 observed, 24.5 expected, $P<0.01)$ and lung cancers $(131$ observed, $97 \cdot 7$ expected, $P<0 \cdot 001)$. For $1972-74$ the significant excess of all cancers is confirmed (246 observed, 205.6 expected, $\mathbf{P}<0.01$ ) as is that for lung cancer (117 observed, 91.8 expected, $P<0.01)$. The excess in stomach cancers is not confirmed (25 observed, 22.2 expected, $P>0.05$ ) but for 1972-74 there is a significant excess of bladder cancers (13 observed, $7 \cdot 1$ expected, $P<0.05)$ and an indication of an excess in cancers of other urinary organs (7 observed, 3.7 expected, $P>0.05$ ).

Table 2-continued

\begin{tabular}{|c|c|c|c|c|c|c|c|c|c|c|c|c|}
\hline \multirow{2}{*}{ Exposure group } & \multicolumn{3}{|c|}{1971} & \multicolumn{3}{|c|}{1972} & \multicolumn{3}{|c|}{1973} & \multicolumn{3}{|c|}{1974} \\
\hline & Observed & $S M R$ & Expected & Observed & $S M R$ & Expected & Observed & $S M R$ & Expected & Observed & $S M R$ & Expected \\
\hline \multirow{5}{*}{$\begin{array}{l}\text { Group A } \\
\text { Exposed to } \\
\text { carcinogens } \\
\text { Group B } \\
\text { Not exposed but } \\
\text { firm used carcinogens } \\
\text { Group C } \\
\text { Firm never used } \\
\text { carcinogens }\end{array}$} & 1 & & $2 \cdot 42$ & $6^{1}$ & & $2 \cdot 45$ & 5 & & $2 \cdot 58$ & 5 & & $2 \cdot 80$ \\
\hline & \multicolumn{3}{|c|}{41} & \multicolumn{3}{|c|}{245} & \multicolumn{3}{|c|}{194} & \multicolumn{3}{|c|}{179} \\
\hline & \multicolumn{3}{|c|}{144} & \multicolumn{3}{|c|}{92} & \multicolumn{3}{|c|}{219} & \multicolumn{3}{|c|}{241} \\
\hline & - & & $1 \cdot 27$ & - & & $1 \cdot 31$ & 4 & & $1 \cdot 37$ & 4 & & 1.48 \\
\hline & \multicolumn{3}{|c|}{-} & \multicolumn{3}{|c|}{-} & \multicolumn{3}{|c|}{292} & \multicolumn{3}{|c|}{270} \\
\hline \multirow[t]{2}{*}{ Total industry } & 4 & & 5.77 . & 8 & & $5 \cdot 93$ & $14^{2}$ & & $6 \cdot 22$ & $15^{2}$ & & 6.78 \\
\hline & \multicolumn{3}{|c|}{$69 \cdot 2$} & \multicolumn{3}{|c|}{$118 \cdot 0$} & \multicolumn{3}{|c|}{$225 \cdot 0$} & \multicolumn{3}{|c|}{$221 \cdot 2$} \\
\hline
\end{tabular}


TABLE 3

Observed and Expected Bladder Cancer Deaths and Standardized Mortality RATIOS BY EXPOSURE GrouP AND AGE Group FOR 1968-71 AND 1972-74

\begin{tabular}{|c|c|c|c|c|c|c|c|}
\hline \multirow{2}{*}{$\begin{array}{c}\text { Exposure } \\
\text { group }\end{array}$} & \multirow{2}{*}{$\begin{array}{l}\text { Age group } \\
\text { (years) }\end{array}$} & \multicolumn{3}{|c|}{$1968-71$} & \multicolumn{3}{|c|}{$1972-74$} \\
\hline & & Observed & Expected & $S M R$ & Observed & Expected & $S M R$ \\
\hline Group A & $\begin{array}{l}35-44 \\
45-64 \\
65+ \\
\text { Total }\end{array}$ & $\begin{array}{r}- \\
4 \\
11\end{array}$ & $\begin{array}{l}0.1 \\
5 \cdot 5 \\
2.9 \\
8.5\end{array}$ & $\begin{array}{l}\overline{127} \\
138 \\
129\end{array}$ & $\begin{array}{c}- \\
8^{1} \\
8 \\
16^{2}\end{array}$ & $\begin{array}{l}- \\
3 \cdot 5 \\
4 \cdot 3 \\
7 \cdot 8\end{array}$ & $\begin{array}{l}-229 \\
186 \\
205\end{array}$ \\
\hline Group B & $\begin{array}{l}35-44 \\
45-64 \\
65+ \\
\text { Total }\end{array}$ & $\begin{array}{l}1 \\
4 \\
2 \\
7\end{array}$ & $\begin{array}{l}0 \cdot 2 \\
5 \cdot 1 \\
1.9 \\
7 \cdot 2\end{array}$ & $\begin{array}{r}-79 \\
105 \\
97\end{array}$ & $\begin{array}{c}-7 \\
6 \\
13^{1}\end{array}$ & $\begin{array}{l}0 \cdot 1 \\
3 \cdot 8 \\
3 \cdot 0 \\
6.9\end{array}$ & $\begin{array}{l}-\overline{184} \\
200 \\
188\end{array}$ \\
\hline Group C & $\begin{array}{l}35-44 \\
45-64 \\
65+ \\
\text { Total }\end{array}$ & $\begin{array}{l}- \\
4 \\
1 \\
5\end{array}$ & $\begin{array}{l}0 \cdot 1 \\
3 \cdot 0 \\
1 \cdot 3 \\
4 \cdot 4\end{array}$ & $\begin{array}{r}-133 \\
77 \\
114\end{array}$ & $\begin{array}{r}- \\
5 \\
3 \\
8\end{array}$ & $\begin{array}{l}0 \cdot 1 \\
2 \cdot 2 \\
1 \cdot 9 \\
4 \cdot 2\end{array}$ & $\begin{array}{l}-227 \\
158 \\
190\end{array}$ \\
\hline & Total survey & 23 & $20 \cdot 0$ & 115 & $37^{3}$ & 18.9 & 196 \\
\hline
\end{tabular}

${ }^{1} \mathrm{P}<0.05$.

${ }^{2} \mathrm{P}<0.01$.

${ }^{3} \mathrm{P}<0.001$.

TABLE 4

Guide to the Sectors of the Industry Meriting Detailed Study on the Bases of Deaths Occurring According to Certified Causes in 1968-74

\begin{tabular}{|c|c|c|c|c|c|c|c|c|c|c|c|c|}
\hline \multirow[t]{2}{*}{ ICD No. } & \multicolumn{2}{|c|}{ Tyres } & \multicolumn{2}{|c|}{$\begin{array}{l}\text { Tyre remoulds } \\
\text { and retreads }\end{array}$} & \multicolumn{2}{|c|}{$\begin{array}{c}\text { Cables and } \\
\text { electrical goods }\end{array}$} & \multicolumn{2}{|c|}{$\begin{array}{l}\text { Adhesives, rubber } \\
\text { solations, and } \\
\text { sealing } \\
\text { compounds }\end{array}$} & \multicolumn{2}{|c|}{$\begin{array}{c}\text { Clothing } \\
\text { rubberized } \\
\text { textiles, } \\
\text { rubberized hair } \\
\text { and carpeting }\end{array}$} & \multicolumn{2}{|c|}{$\begin{array}{l}\text { Belting, hose } \\
\text { rubber with } \\
\text { asbestos, flooring }\end{array}$} \\
\hline & Observed & Expected ${ }^{*}$ & Observed & Expected" & Observed & Expected ${ }^{*}$ & Observed & Expected $*$ & Observed & Expected $*$ & Observed & Expected ${ }^{*}$ \\
\hline $\begin{array}{l}140-239 \\
150- \\
151 \\
155 \\
1621 \\
188 \\
189 \\
191 \\
204-207 \\
240-279 \\
390-458 \\
410-414 \\
460-519 \\
490-493 \\
520-577 \\
570-573 \\
800-949 \\
950-959\end{array}$ & $\left.\begin{array}{c}519^{3} \\
8 \\
65^{1} \\
2 \\
248^{3} \\
20 \\
10 \\
10 \\
11 \\
12 \\
745 \\
533 \\
163 \\
103 \\
31 \\
11 \\
35 \\
13\end{array}\right\}$ & $\begin{array}{r}434 \cdot 0 \\
11 \cdot 6 \\
48 \cdot 0 \\
2 \cdot 6 \\
193 \cdot 6 \\
15 \cdot 3 \\
7 \cdot 6 \\
9 \cdot 3 \\
9 \cdot 1 \\
13 \cdot 3 \\
793 \cdot 6 \\
538 \cdot 9 \\
193 \cdot 8 \\
104 \cdot 4 \\
38 \cdot 3 \\
8 \cdot 4 \\
54 \cdot 3\end{array}$ & $\left.\begin{array}{r}\frac{29}{2} \\
\frac{2}{16} \\
1 \\
\frac{1}{2} \\
1 \\
35 \\
20 \\
6 \\
5 \\
5 \\
2 \\
4 \\
-\end{array}\right\}$ & $\begin{array}{r}24 \cdot 7 \\
0 \cdot 7 \\
2 \cdot 7 \\
0 \cdot 1 \\
11 \cdot 0 \\
0.9 \\
0 \cdot 4 \\
0 \cdot 5 \\
0 \cdot 5 \\
0 \cdot 8 \\
45 \cdot 1 \\
30 \cdot 6 \\
11 \cdot 0 \\
5.9 \\
2 \cdot 2 \\
0.5 \\
3 \cdot 1\end{array}$ & $\left.\begin{array}{r}75 \\
1 \\
11 \\
1 \\
32 \\
6^{1} \\
- \\
- \\
1 \\
3 \\
132 \\
87 \\
36 \\
24^{1} \\
2 \\
-3 \\
1\end{array}\right\}$ & $\begin{array}{r}67.8 \\
1.8 \\
7.5 \\
0 \cdot 4 \\
30 \cdot 3 \\
2.4 \\
1.2 \\
1.5 \\
1.4 \\
2.1 \\
124 \cdot 0 \\
84 \cdot 2 \\
30 \cdot 3 \\
16.3 \\
6.0 \\
1.3 \\
8.5\end{array}$ & 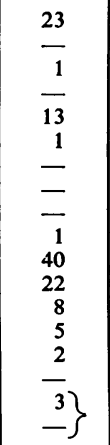 & $\begin{array}{r}21.0 \\
0.6 \\
2.3 \\
0.1 \\
9.4 \\
0.7 \\
0.4 \\
0.5 \\
0.4 \\
0.6 \\
38.5 \\
26.1 \\
9.4 \\
5.1 \\
1.9 \\
0.4 \\
2.6\end{array}$ & $\left.\begin{array}{c}53 \\
6 \\
-27 \\
1 \\
-1 \\
1 \\
1 \\
113^{1} \\
80^{1} \\
20 \\
11 \\
2 \\
-4 \\
-\end{array}\right\}$ & $\begin{array}{r}49.0 \\
1.3 \\
5.4 \\
0.3 \\
21.9 \\
1.7 \\
0.9 \\
1.1 \\
1.0 \\
1.5 \\
89.6 \\
60.9 \\
21.9 \\
11.8 \\
4.3 \\
0.9 \\
6.1\end{array}$ & $\left.\begin{array}{c}140^{1} \\
1 \\
17 \\
77^{1} \\
2 \\
3 \\
1 \\
2 \\
5 \\
248^{1} \\
169 \\
56 \\
39^{1} \\
11 \\
4 \\
12 \\
4\end{array}\right\}$ & $\begin{array}{r}117 \cdot 7 \\
3.1 \\
13.0 \\
0.7 \\
52.5 \\
4.2 \\
2.1 \\
2.5 \\
2.5 \\
3.6 \\
215.3 \\
146.2 \\
52.6 \\
28.3 \\
10.4 \\
2.3 \\
14.7\end{array}$ \\
\hline All deaths & 1571 & $1591 \cdot 3$ & 83 & $90 \cdot 5$ & 260 & $248 \cdot 7$ & 80 & $77 \cdot 1$ & 198 & $179 \cdot 7$ & $488^{2}$ & $431 \cdot 7$ \\
\hline Total population 1967 & \multicolumn{2}{|c|}{16035} & \multicolumn{2}{|c|}{912} & \multicolumn{2}{|c|}{2506} & \multicolumn{2}{|c|}{777} & \multicolumn{2}{|c|}{1811} & \multicolumn{2}{|c|}{4350} \\
\hline
\end{tabular}

* Expected deaths based on the proportion of people in particular industrial groups multiplied by the total number of deaths expected for the cause of interest, for example, 140-239 (all neoplasms) for group 1 is 1106.0 (all neoplasms expected) $\times 16035 \div 40867=433.96$.

${ }^{1} \mathrm{P}<0.05$.

${ }^{2} P<0.01$.

${ }^{3} \mathbf{P}<0.001$. 
In Table 6 the observed and expected deaths for 1968-71 and 1972-74 for the tyre sector are contrasted with those for the remainder of the study population according to exposure to recognized bladder carcinogens. For the 1968-71 period significant excesses were found for all cancers for men in exposure group B, that is, those who entered after 1949 firms which had used the recognized bladder carcinogens. The excess in the tyre sector (126 observed, 87.4 expected, $P<0.001$ ) was greater than that for the remainder of the population studied (150 observed, 124.4 expected, $\mathrm{P}<0.05$ ). Although for 1972-74 the SMR for the tyre sector is as high as that for the remainder of the industry it is only significantly raised for the latter (140 observed, $117 \cdot 1$ expected, $P<0.05$ ). The excessess of stomach cancers observed in 1968-71 for both tyres $(16$ observed, 9.7 expected, $P<0.05)$ and the remainder of the population (21 observed, 14.0 expected, $\mathrm{P}<0.05)$ are not apparent in 1972-74. The excesses in lung cancer in the tyre sector (64 observed, 38.4 expected, $\mathbf{P}<0.001)$ and the remainder of the industry (71 observed, 55.2 expected, $P<0.05)$ are however both confirmed in 1972-74
(55 observed, 37.4 expected, $P<0.01$; and 69 observed, 51.5 expected, $P<0.05$, respectively). The excess in the tyre sector is greater than that for the remainder of the population studied but not significantly so $(P>0.05)$.

For those men who entered firms using recognized bladder carcinogens before 1950, group A, there was a significant excess in 1968-71 in the tyre sector of cancer of the stomach ( 23 observed, 14.4 expected, $P<0.05)$. For 1972-74 this excess is no longer apparent (16 observed, 12.8 expected, $\mathrm{P}>0.05$ ). There is a significant excess of all deaths (23 observed, 13.6 expected, $P<0.05)$ and of all cancers $(8$ observed, 3.7 expected, $P<0.01$ ) for $1972-74$ in men employed in firms in the tyre sector which have never used the known carcinogens. This excess may also be associated with a not significant excess of lung cancers (4 observed, 1.6 expected, $P>0.05)$.

In Table 7 the observed and expected deaths from lung cancer for men in exposure group $B$ in the tyre sector are shown according to age for 1968-71 and 1972-74. These are compared with the corresponding figures for the rest of the population studied. Although for the tyre sector more deaths are

Table 4-continued

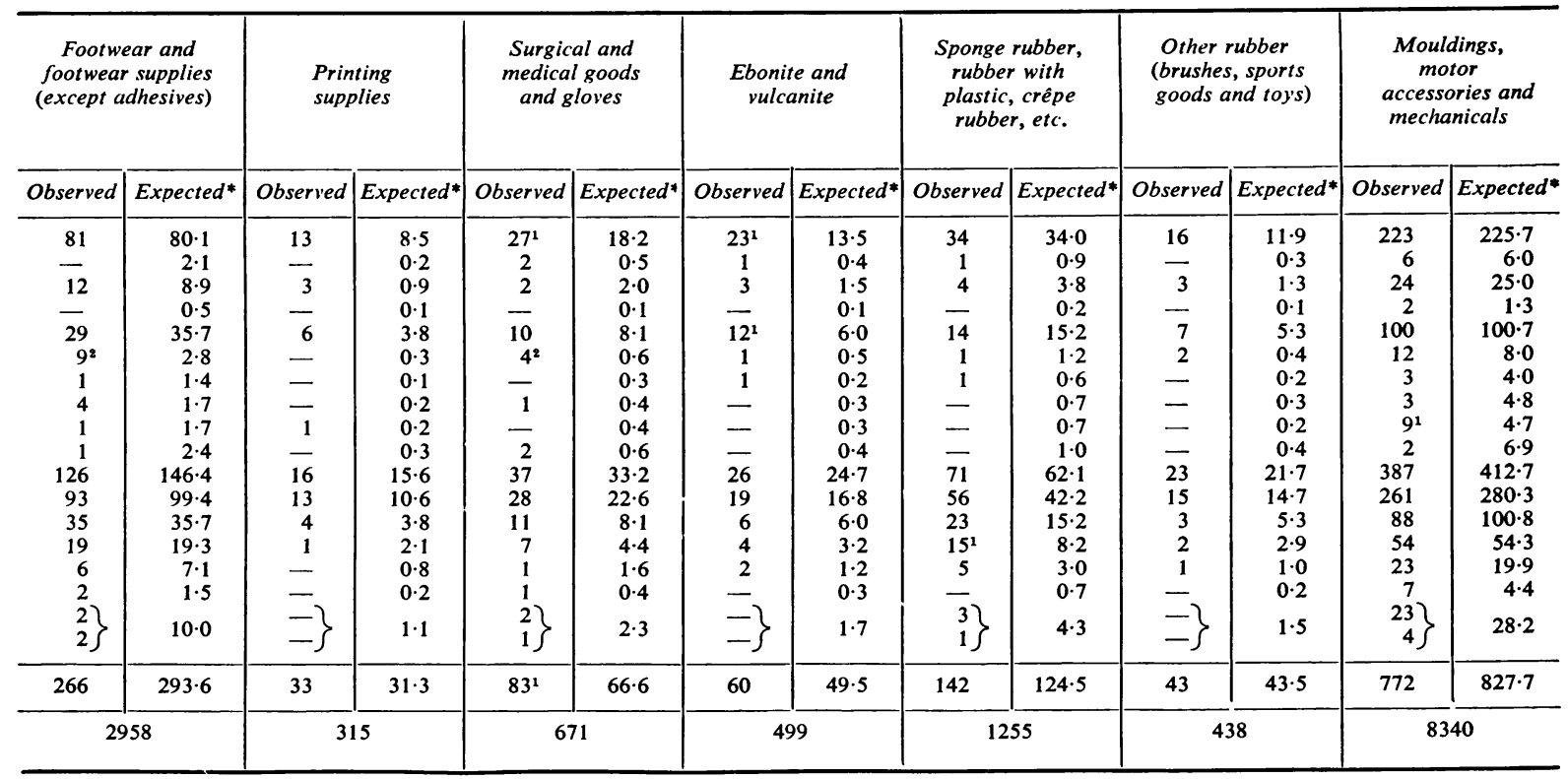


TABLE 5

Observed and Expected Deaths for Men Employed in the Tyre Sector ACCORDING to CERTIFIED CAUSE FOR 1968-71 AND 1972-74

\begin{tabular}{|c|c|c|c|c|c|c|c|c|}
\hline \multirow{2}{*}{\multicolumn{3}{|c|}{$\begin{array}{l}\text { Cause of death } \\
\quad(I C D \text { No.) }\end{array}$}} & \multicolumn{3}{|c|}{$1968-71$} & \multicolumn{3}{|c|}{$1972-74$} \\
\hline & & & Observed & Expected & $S M R$ & Observed & Expected & $S M R$ \\
\hline 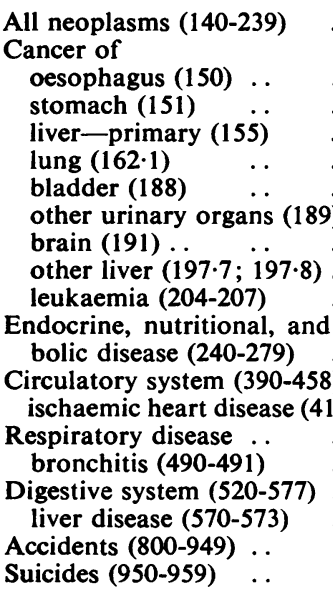 & 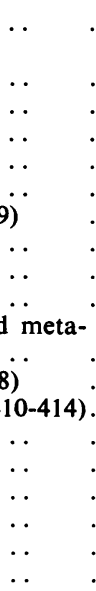 & 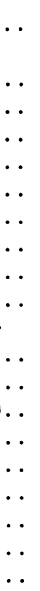 & $\begin{array}{c}273^{3} \\
3 \\
3 \\
40^{2} \\
1 \\
131^{3} \\
7 \\
3 \\
6 \\
2 \\
5 \\
8 \\
366 \\
256 \\
78 \\
44 \\
12 \\
3 \\
21 \\
8\end{array}$ & $\begin{array}{r}217 \cdot 2 \\
5 \cdot 6 \\
24 \cdot 5 \\
1 \cdot 3 \\
97 \cdot 7 \\
7 \cdot 5 \\
3 \cdot 8 \\
5 \cdot 1 \\
1 \cdot 4 \\
4 \cdot 7 \\
\\
6 \cdot 3 \\
383 \cdot 4 \\
262 \cdot 2 \\
94 \cdot 7 \\
53 \cdot 7 \\
18 \cdot 4 \\
4 \cdot 1 \\
21 \cdot 2 \\
10 \cdot 2\end{array}$ & $\begin{array}{r}125 \cdot 7 \\
53 \cdot 6 \\
163 \cdot 3 \\
76 \cdot 9 \\
134 \cdot 1 \\
93 \cdot 3 \\
78 \cdot 9 \\
117 \cdot 6 \\
142 \cdot 9 \\
106 \cdot 4 \\
\\
127 \cdot 0 \\
95 \cdot 9 \\
97 \cdot 6 \\
82 \cdot 4 \\
81 \cdot 9 \\
65 \cdot 2 \\
73 \cdot 2 \\
99 \cdot 1 \\
78 \cdot 4\end{array}$ & $\begin{array}{r}246^{2} \\
5 \\
5 \\
25 \\
1 \\
117^{2} \\
13^{1} \\
7 \\
4 \\
2 \\
6 \\
\\
4 \\
379 \\
277 \\
85 \\
51 \\
19 \\
3 \\
14 \\
5\end{array}$ & $\begin{array}{r}205 \cdot 6 \\
\\
5 \cdot 7 \\
22 \cdot 2 \\
1 \cdot 3 \\
91 \cdot 8 \\
7 \cdot 1 \\
3 \cdot 7 \\
4 \cdot 2 \\
1 \cdot 3 \\
4 \cdot 2 \\
\\
6 \cdot 5 \\
378 \cdot 7 \\
260 \cdot 9 \\
87 \cdot 0 \\
45 \cdot 3 \\
17 \cdot 9 \\
4 \cdot 2 \\
15 \cdot 7 \\
6.7\end{array}$ & $\begin{array}{r}119 \cdot 6 \\
\\
87 \cdot 7 \\
112 \cdot 6 \\
76 \cdot 9 \\
127 \cdot 5 \\
183 \cdot 1 \\
189 \cdot 2 \\
95 \cdot 2 \\
153 \cdot 8 \\
142 \cdot 9 \\
\\
61 \cdot 5 \\
100 \cdot 1 \\
106 \cdot 2 \\
97 \cdot 7 \\
112 \cdot 6 \\
106 \cdot 1 \\
71 \cdot 4 \\
89 \cdot 2 \\
74 \cdot 6\end{array}$ \\
\hline All deaths & . & . & 794 & $785 \cdot 7$ & $101 \cdot 1$ & 777 & $747 \cdot 3$ & $104 \cdot 0$ \\
\hline
\end{tabular}

${ }^{1} \mathbf{P}<0.05$.

${ }^{2} \mathbf{P}<0.01$.

${ }^{3} \mathbf{P}<0.001$.

observed than expected in every age group for both periods, 1968-71 and 1972-74, the 55-64-year age group contains the only significant excesses. These are significant for both 1968-71 (40 observed, 21·1 expected, $P<0.001)$ and 1972-74 (29 observed, 18.1 expected, $P<0.05$ ). For the remainder of the population studied there is also a significant excess for 1972-74 in the 55-64-year age group (39 observed, 23.2 expected, $P<0.01$ ) and in the 65 -year plus age group for 1968-71 (21 observed, 13.0 expected, $\mathbf{P}<0.05$ ).

In Table 8 the observed and age-standardized expected deaths in 1972-74 for particular causes in the tyre sector are compared with those for the remainder of the population studied according to the year of entry into the industry. For the remainder of the population studied there is a significant excess of bladder cancers for the pre-1940 group (7 observed, 2.4 expected, $P<0.05)$ and for the 1945-49 group ( 6 observed, 1.8 expected, $P<0.05$ ). There is also a significant excess of all cancers in the 196064 group ( 88 observed, 69.5 expected, $P<0.05$ ). For the tyre sector there is a significant excess of bladder cancers for 1940-44 (3 observed, 0.6 expected, $P<0.05$ ), and for all cancers and lung cancers for 1955-59 (40 observed, 26.5 expected, $P<0.05$; and
19 observed, 11.6 expected, $P<0.05$, respectively). The SMR for all cancers for workers in the tyre sector is consistently higher than that for the remainder of the population studied except in 1940-44 and 1960-64. The corresponding SMRs for lung cancer are also consistently higher for the tyre sector than for the remainder of the population studied except in 1940-44. The excess in lung cancers in the tyre sector appears particularly high for 1950-54 and 1955-59 for which the SMRs are 151 and 164 for the tyre sector, compared with 111 and 91 for the remainder of the population studied.

The two job groups in the tyre sector found in 1968-71 to share the greatest excess in lung cancer deaths were moulding, press, autoclave and pan curemen, and finished goods, packaging and despatch. In Table 9 mortality experience in these two groups for 1972-74 is considered according to age group. The SMRs for lung cancer in both these job groups are lower compared with 1968-71. In the former group whereas 15 deaths due to lung cancer were observed in 1968-71 compared with 8.4 expected, there were nine such deaths observed in 1972-74 compared with $8 \cdot 1$ expected. In the latter group whereas 13 deaths due to lung cancer were observed compared with 6.8 expected in 1968-71, eight were 


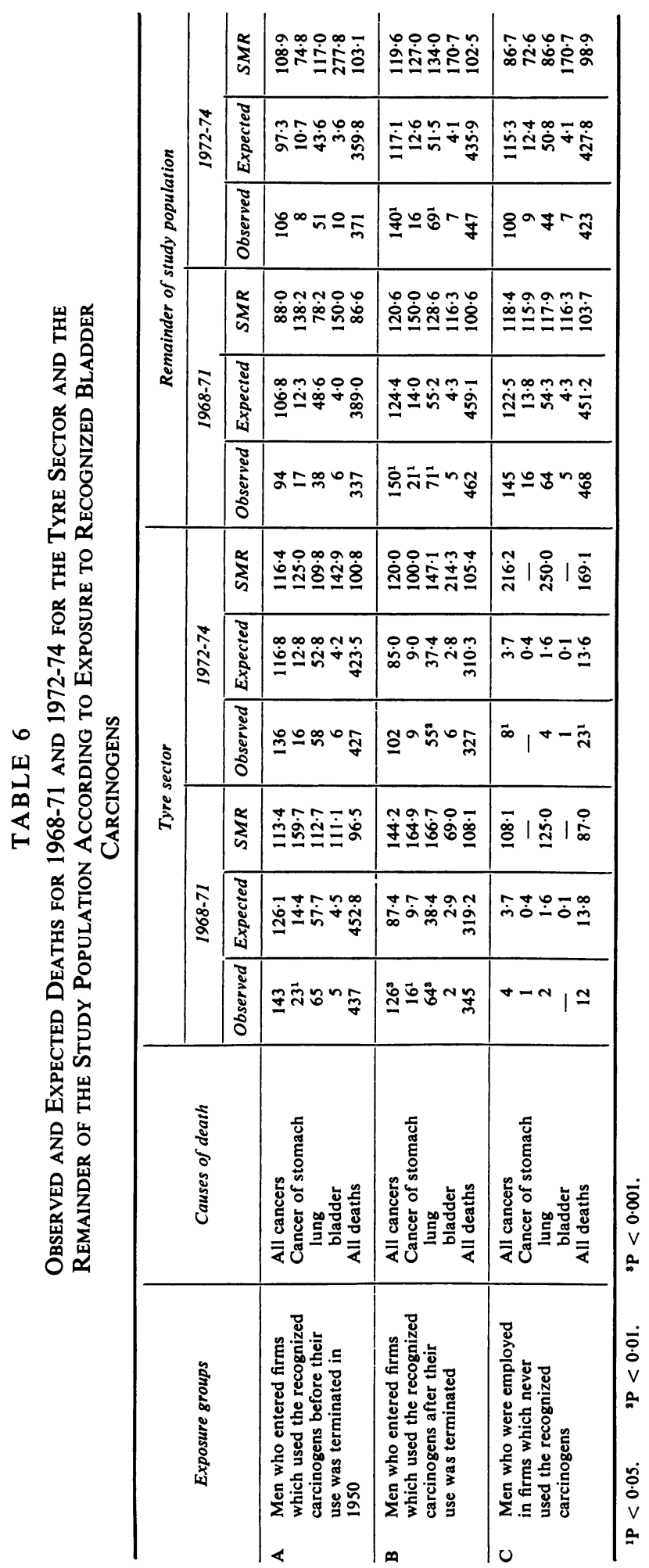




\section{TABLE 7}

Observed and Expected Deaths from lung Cancer in Men in Exposure Group B, that is, Men Who Entered After 1950 into Firms Which Used ReCognized Bladder Carcinogens, Comparing the Tyre Sector with the Remainder of the Population

STUDIED

\begin{tabular}{|c|c|c|c|c|c|c|c|c|c|c|c|c|}
\hline \multirow{3}{*}{$\begin{array}{c}\text { Age group } \\
\text { (years) }\end{array}$} & \multicolumn{6}{|c|}{ Tyre sector } & \multicolumn{6}{|c|}{ Remainder of study population } \\
\hline & \multicolumn{3}{|c|}{$1968-71$} & \multicolumn{3}{|c|}{$1972-74$} & \multicolumn{3}{|c|}{$1968-71$} & \multicolumn{3}{|c|}{$1972-74$} \\
\hline & Observed & Expected & $S M R$ & Observed & Expected & $S M R$ & Observed & Expected & $S M R$ & Observed & Expected & $S M R$ \\
\hline $\begin{array}{l}35-44 \\
45-54 \\
55-64 \\
65+\end{array}$ & $\begin{array}{c}2 \\
13 \\
40^{3} \\
9\end{array}$ & $\begin{array}{r}1.9 \\
9.9 \\
21.1 \\
5.5\end{array}$ & $\begin{array}{l}105 \\
131 \\
190 \\
164\end{array}$ & $\begin{array}{c}2 \\
8 \\
29^{1} \\
16\end{array}$ & $\begin{array}{r}0.9 \\
7.9 \\
18 \cdot 1 \\
10 \cdot 5\end{array}$ & $\begin{array}{l}222 \\
101 \\
160 \\
152\end{array}$ & $\begin{array}{c}4 \\
11 \\
35 \\
21^{1}\end{array}$ & $\begin{array}{r}1 \cdot 7 \\
10.9 \\
29 \cdot 6 \\
13.0\end{array}$ & $\begin{array}{l}235 \\
101 \\
118 \\
161\end{array}$ & $\begin{array}{c}\overline{9} \\
39^{2} \\
21\end{array}$ & $\begin{array}{r}0 \cdot 7 \\
8 \cdot 1 \\
23 \cdot 2 \\
19 \cdot 5\end{array}$ & $\begin{array}{l}\overline{111} \\
168 \\
108\end{array}$ \\
\hline Total & $64^{3}$ & $38 \cdot 4$ & 167 & $55^{2}$ & $37 \cdot 4$ & 147 & $71^{1}$ & $55 \cdot 2$ & 129 & $69^{1}$ & $51 \cdot 5$ & 134 \\
\hline
\end{tabular}

${ }^{1} \mathrm{P}<0.05$.

${ }^{2} \mathrm{P}<0.01$

${ }^{3} \mathbf{P}<0.001$.

observed in 1972-74 compared with 6.2 expected. The only difference in 1972-74 which attained statistical significance was an excess in all deaths for finished goods, packaging and despatch in the 35-44-year age group (3 observed, 0.8 expected, $P<0.05)$.

Further comparisons of these two job groups between 1972-74 and 1968-71 indicate that the mortality patterns are similar in terms of SMRs but that more deaths are expected in the older age group than were expected in 1968-71. The population is on average $3 \frac{1}{2}$ years older than that of the previous analysis. For moulding, press, autoclave, and pan curemen the SMRs for all cancers and for cancers of the lung are higher whereas those for all causes are lower than expected. For finished goods, stores, and packaging despatch men in the tyre sector all SMRs are higher.

Other sectors with excesses

In Table 10 the observed and age-standardized expected deaths by cause for 1972-74 are given for the sectors of the industry indicated in Table 4 as having more deaths from particular causes.

The SMR for neoplasms of the bladder for men working with cables and electrical goods is the same for 1972-74 as for 1968-74 but because of the small numbers involved (only three deaths observed in 1972-74) this is not significant. Table 4 showed an excess of deaths from circulatory disease for men working in clothing, rubberized textiles, rubberized hair, and carpeting and for 1972-74 62 deaths were observed from this cause in the group, compared with 50.9 expected. Of these, 43 were due to ischaemic heart disease (ICD 410-414) compared with 34.1 expected. Although these rates are not significant, they are so when combined with the deaths for 1968-71 (P < 0.05).

The increased number of lung cancers noted in the previous repolt for belting, hose rubber with asbestos, and flooring appears again in Table 4. Table 10 indicates that a lower excess which is not

TABLE 8

Observed and Age Standardized Expected Deaths According to Year of Entry for 1972-74 FOR tHOSE MEN EMPLOYED IN THE TYRE SeCtOR COMPARED WITH THE ReMAINDER OF THE POPUlation STUdied

\begin{tabular}{|c|c|c|c|c|c|c|c|c|c|c|c|c|}
\hline \multirow{3}{*}{ Year of entry } & \multicolumn{12}{|c|}{ Tyre sector } \\
\hline & \multicolumn{3}{|c|}{ All deaths } & \multicolumn{3}{|c|}{ All cancers } & \multicolumn{3}{|c|}{ Lung cancer } & \multicolumn{3}{|c|}{ Bladder cancer } \\
\hline & Observed & Expected & $S M R$ & Observed & Expected & $S M R$ & Observed & Expected & $S M R$ & Observed & Expected & $S M R$ \\
\hline $\begin{array}{l}\text { Pre-1940 } \\
1940-44 \\
1945-49 \\
1950-54 \\
1955-59 \\
1960-64 \\
1965-66\end{array}$ & $\begin{array}{r}187 \\
65 \\
176 \\
125 \\
109 \\
86 \\
30\end{array}$ & $\begin{array}{r}196.4 \\
59 \cdot 3 \\
168 \cdot 6 \\
119.6 \\
96 \cdot 5 \\
83 \cdot 1 \\
25 \cdot 0\end{array}$ & $\begin{array}{r}95 \\
110 \\
104 \\
105 \\
113 \\
103 \\
120\end{array}$ & $\begin{array}{l}68 \\
17 \\
51 \\
33 \\
40^{2} \\
28 \\
10\end{array}$ & $\begin{array}{r}54 \cdot 4 \\
16 \cdot 3 \\
46 \cdot 3 \\
32 \cdot 9 \\
26 \cdot 5 \\
22 \cdot 7 \\
6 \cdot 8\end{array}$ & $\begin{array}{l}125 \\
104 \\
110 \\
100 \\
151 \\
123 \\
147\end{array}$ & $\begin{array}{c}27 \\
4 \\
27 \\
22^{1} \\
19^{1} \\
14 \\
5\end{array}$ & $\begin{array}{r}24.8 \\
7.4 \\
20.8 \\
14.6 \\
11.6 \\
9.9 \\
2.9\end{array}$ & $\begin{array}{r}109 \\
54 \\
130 \\
151 \\
164 \\
141 \\
172\end{array}$ & $\begin{array}{l}2 \\
3^{1} \\
1 \\
2 \\
3 \\
2 \\
-\end{array}$ & $\begin{array}{l}2.0 \\
0.6 \\
1.6 \\
1.1 \\
0.9 \\
0.7 \\
0.2\end{array}$ & $\begin{array}{r}100 \\
500 \\
63 \\
182 \\
333 \\
286 \\
-\end{array}$ \\
\hline
\end{tabular}

$1 P<0.05$.

$P<0.01$. 
statistically significant is observed for 1972-74. The respiratory disease rate for $1972-74$ is however high (32 observed compared with 23.2 expected) but not significant. It will be necessary to monitor this group closely to see whether or not the overall high mortality rate continues during the next few years.

The evidence of there being more cases of cancer in men dealing with printing supplies suggested in the previous report is not confirmed in this analysis and the excesses of all cancers, bladder cancers, and all other causes for men dealing with surgical and medical goods and gloves are also not apparent for the period 1972-74 on its own. These last two groups are particularly small. If the total data for 1968-74 are combined the excess of bladder cancers for men working with surgical and medical goods and gloves is significant (4 observed, 0.7 expected, $P<0.05$ ). Three of these cases were persons employed in firms which had never used the known bladder carcinogens.

Table 10 indicates that there was for 1972-74 a highly significant excess of neoplasms of the bladder in footwear and footwear supplies except adhesives (7 observed, 1.3 expected, $P<0.001$ ). This excess is primarily in exposure groups A (3 observed, 0.5 expected, $\mathrm{P}<0.05$ ) and $\mathrm{B}$ ( 3 observed, 0.4 expected, $P<0.01$ ), that is, in those firms which previously used the known carcinogens. The other three neoplasms of the bladder that have occurred in this group between 1968-74 all occurred in exposure group C, that is, firms that had never used the known carcinogens.

The detailed analysis of the 1972-74 mortality of workers in ebonite and vulcanite would indicate an excess of all neoplasms (14 observed, $7 \cdot 3$ expected, $P<0.05)$, particularly lung cancer ( 7 observed, $3 \cdot 2$ expected, $P<0.05)$, and all causes (37 observed, 26.9 expected, $P<0.05$ ). These excesses are not apparent from the 1968-71 analysis but will merit close attention in future analyses.

A significant excess of all causes of death for 1972-74 is observed for workers in sponge rubber, rubber with plastic, crêpe rubber, etc. (80 observed, 61.9 expected, $P<0.05)$. There are high rates for all causes, in particular circulatory disease (42 observed, 31.4 expected, $P<0.05$ ) and respiratory disease (13 observed, 7.6 expected, $P<0.05$ ).

\section{Geographical distribution}

A possible explanation for the high lung cancer SMR is that a comparatively high proportion of men live in the conurbations of Tyneside, west Yorkshire, south east Lancashire, Merseyside, West Midlands, and Greater London. Table 11 gives the population distribution among these conurbations for all sectors of the industry, the tyre sector, and the total England and Wales male population aged 35-64 years in 1967. The percentages working in conurbations are $45.5 \%$ for all sectors and $70.1 \%$ for the tyre sector, compared with the lower percentage of $35.1 \%$ for all England and Wales. Table 11 also shows that the lung cancer SMR for the conurbations is approximately 120 . A crude attempt can be made to calculate the effect of living in a conurbation by multiplying the expected number of lung cancer deaths by:

$$
\begin{array}{r}
\frac{1}{100}[\mathrm{pr} \times(\mathrm{SMR} \text { for conurbation areas })+(1-\mathrm{pr}) \\
\times(\mathrm{SMR} \text { for non-conurbation areas })]
\end{array}
$$

where $\mathrm{pr}=$ proportion of people in the study population.

Taking the lung cancer SMR for conurbations to be 120 and for non-conurbation areas to be 89 (which is consistent with $35.1 \%$ living in conurbations) the multiplicative factors are 1.03 for all sectors of the industry and 1.11 for the tyre sector.

\begin{tabular}{|c|c|c|c|c|c|c|c|c|c|c|c|c|}
\hline \multirow{3}{*}{ Year of entry } & \multicolumn{12}{|c|}{ Remainder of study population } \\
\hline & \multicolumn{3}{|c|}{ All deaths } & \multicolumn{3}{|c|}{ All cancers } & \multicolumn{3}{|c|}{ Lung cancer } & \multicolumn{3}{|c|}{ Bladder cancer } \\
\hline & Observed & Expected & $S M R$ & Observed & Expected & $S M R$ & Observed & Expected & $S M R$ & Observed & Expected & $S M R$ \\
\hline $\begin{array}{l}\text { Pre-1940 } \\
1940-44 \\
1945-49 \\
1950-54 \\
1955-59 \\
1960-64 \\
1965-66\end{array}$ & $\begin{array}{r}232 \\
64 \\
180 \\
200 \\
188 \\
284 \\
97\end{array}$ & $\begin{array}{r}234 \cdot 2 \\
58 \cdot 6 \\
180 \cdot 6 \\
187 \cdot 6 \\
204 \cdot 6 \\
259 \cdot 7 \\
100 \cdot 1\end{array}$ & $\begin{array}{r}99 \\
109 \\
100 \\
107 \\
92 \\
109 \\
97\end{array}$ & $\begin{array}{l}69 \\
17 \\
48 \\
49 \\
52 \\
88^{1} \\
27\end{array}$ & $\begin{array}{l}63 \cdot 2 \\
15 \cdot 6 \\
49 \cdot 3 \\
51 \cdot 0 \\
55 \cdot 0 \\
69 \cdot 5 \\
26 \cdot 5\end{array}$ & $\begin{array}{r}109 \\
109 \\
97 \\
96 \\
95 \\
127 \\
102\end{array}$ & $\begin{array}{r}28 \\
9 \\
27 \\
25 \\
22 \\
40 \\
15\end{array}$ & $\begin{array}{r}28 \cdot 4 \\
6 \cdot 9 \\
22 \cdot 0 \\
22 \cdot 6 \\
24 \cdot 3 \\
30 \cdot 3 \\
11 \cdot 6\end{array}$ & $\begin{array}{r}99 \\
130 \\
123 \\
111 \\
91 \\
132 \\
129\end{array}$ & $\begin{array}{l}71 \\
1 \\
61 \\
1 \\
4 \\
3 \\
2\end{array}$ & $\begin{array}{l}2.4 \\
0.6 \\
1.8 \\
1.8 \\
1.9 \\
2.4 \\
0.9\end{array}$ & $\begin{array}{r}292 \\
167 \\
333 \\
56 \\
211 \\
125 \\
222\end{array}$ \\
\hline
\end{tabular}

Table 8-continued 

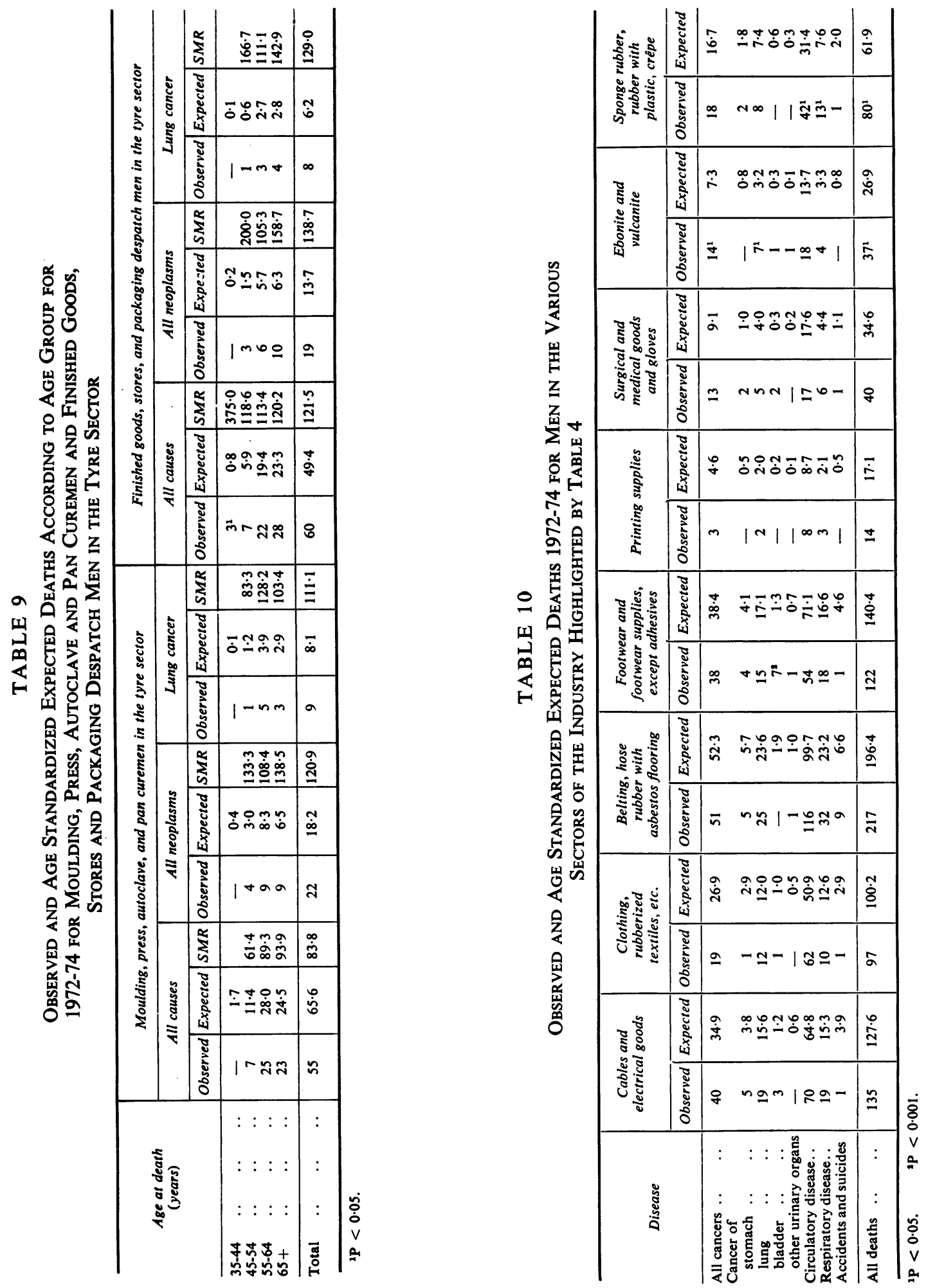


\section{TABLE 11}

Population Distribution (Excluding Scotland) among Six Conurbations, for All Sectors, the Tyre Sector, and the whole England and Wales Male

POPUlation (AGED 35-64 in 1967)

\begin{tabular}{|c|c|c|c|c|c|c|c|c|c|c|c|c|}
\hline \multirow{3}{*}{\multicolumn{2}{|c|}{$\begin{array}{c}\text { Conurbation } \\
\text { (as defined by the } \\
\text { Registrar General, 1968-73) }\end{array}$}} & \multicolumn{4}{|c|}{ Rubber survey population } & \multirow{2}{*}{\multicolumn{2}{|c|}{$\begin{array}{c}\text { Total England and Wales } \\
\text { male population } \\
\text { (aged 35-64 in 1967) }\end{array}$}} & \multirow{2}{*}{\multicolumn{5}{|c|}{$\begin{array}{l}\text { Standardized mortality ratios } \\
\quad \text { for lung cancer }\end{array}$}} \\
\hline & & \multicolumn{2}{|c|}{ All sectors } & \multicolumn{2}{|c|}{ Tyre sector } & & & & & & & \\
\hline & & No. & $\% *$ & No. & $\%^{*}$ & No. & $\% *$ & 1968 & 1969 & 1970 & 1971 & 1972 \\
\hline $\begin{array}{lc}\text { Tyneside } & . . \\
\text { West Yorkshire } & . \\
\text { South East Lancashire } \\
\text { Merseyside } & . . \\
\text { West Midlands } & . \\
\text { Greater London } & .\end{array}$ & $\begin{array}{l}\cdots \\
\cdots \\
\cdots \\
\cdots \\
\cdots \\
\cdots\end{array}$ & $\begin{array}{r}1090 \\
260 \\
4065 \\
2930 \\
6200 \\
2965\end{array}$ & $\begin{array}{r}2 \cdot 8 \\
0 \cdot 7 \\
10 \cdot 6 \\
7 \cdot 6 \\
16 \cdot 1 \\
7 \cdot 7\end{array}$ & $\begin{array}{r}- \\
\overline{8} \\
2250 \\
5500 \\
1295\end{array}$ & $\begin{array}{r}0 \cdot 0 \\
0 \cdot 0 \\
6 \cdot 3 \\
16 \cdot 0 \\
39 \cdot 2 \\
9 \cdot 2\end{array}$ & $\begin{array}{r}155900 \\
322800 \\
454200 \\
229000 \\
461700 \\
1500700\end{array}$ & $\begin{array}{r}1 \cdot 8 \\
3 \cdot 6 \\
5 \cdot 1 \\
2 \cdot 6 \\
5 \cdot 2 \\
16 \cdot 9\end{array}$ & $\begin{array}{l}137 \\
102 \\
118 \\
143 \\
115 \\
121\end{array}$ & $\begin{array}{r}129 \\
99 \\
113 \\
130 \\
114 \\
119\end{array}$ & $\begin{array}{l}125 \\
103 \\
121 \\
143 \\
118 \\
119\end{array}$ & $\begin{array}{l}152 \\
107 \\
121 \\
145 \\
108 \\
121\end{array}$ & $\begin{array}{l}145 \\
109 \\
116 \\
135 \\
112 \\
121\end{array}$ \\
\hline All conurbations & .. & 17510 & $45 \cdot 5$ & 9835 & $70 \cdot 1$ & 3124300 & $35 \cdot 1$ & 120 & 117 & 119 & 121 & 120 \\
\hline England and Wales.. & .. & 38460 & $100 \cdot 0$ & 14030 & $100 \cdot 0$ & 8896600 & $100 \cdot 0$ & 100 & 100 & 100 & 100 & 100 \\
\hline
\end{tabular}

*Percentage expressed as a proportion of the population in England and Wales $\times 100$.

Hence the revised expected values and SMRs in Tables 1 and 5 are:

\begin{tabular}{|c|c|c|c|}
\hline & & $1968-71$ & \\
\hline & Observed & Expected & $S M R$ \\
\hline All Sectors & $\begin{array}{c}304 \\
P<0.05\end{array}$ & 263.5 & $115 \cdot 4$ \\
\hline Tyre Sector & $\begin{array}{c}131 \\
P<0.05\end{array}$ & $108 \cdot 5$ & $120 \cdot 8$ \\
\hline & & $1972-74$ & \\
\hline All Sectors & $\begin{array}{c}\text { Observed } \\
281 \\
\mathrm{P}<0.05\end{array}$ & $\begin{array}{c}\text { Expected } \\
244 \cdot 8\end{array}$ & $\begin{array}{l}S M R \\
114 \cdot 8\end{array}$ \\
\hline Гyre Sector & 117 & $101 \cdot 9$ & $114 \cdot 8$ \\
\hline
\end{tabular}

There still remains a high lung cancer SMR implying that this crude method of analysis does not indicate that the excess of lung cancer can be explained completely by a comparatively high proportion of the survey population working in conurbations.

\section{Discussion}

\section{Aims}

A large population was selected in 1967 to cover a wide cross-section of the rubber and cablemaking industry, thereby providing a fast but crude measure of the mortality experience in this industry. Cancer patterns were to be studied in relation to whether or not the firms in which individuals were employed had used previously recognized bladder carcinogens. As the earlier report indicated any hypotheses made in this study should be substantiated later by more detailed studies. The current report is concerned with testing on new data, the deaths occurring between 1972-74, the suggestions generated by our earlier analysis that there is an excess of lung cancer deaths in this population and that it is concentrated in particular sectors of the industry such as the tyre sector. Several new suggestions are put forward and these too will need evaluation. The average age of this rubber and cablemaking population was approximately 50 in 1967 and has now risen to approximately 58 years. Mancuso and El-Attar (1966), in a study of the dynamic changes in industrial cohorts, indicated that care must be taken in comparing SMRs for two periods. The conclusions that we can draw from comparisons of observed and expected deaths for 1968-71 with 1972-74 relate not to the magnitude of the hazard but to the existence of the hazard.

\section{Cancer registration}

The deaths occurring in 1968-71 gave little indication that there were more bladder cancers but the pattern for 1972-74 has altered. The excess in 1973 and 1974 is found in all groups including men who entered the industry after the use of certain recognized carcinogens had been restricted and those who worked in firms which had never used these chemicals. Bladder cancer is generally considered to be amenable to treatment. The ratio of bladder cancer registrations to deaths was 2:1 for 1962-67 (Registrar General, 1972). The ratios were higher in the younger age groups.

The OPCS has been identifying cancer registrations as well as deaths in this population. The delay in notification of the cancer registrations has however meant that detailed analyses cannot yet be performed. The industry through the British Rubber Manufacturers' Association offers urinary cytology to particular groups of workers. It may be argued that this should reduce the death rate from bladder cancer because cases are detected and treated 
earlier. Doctors, on the other hand, aware of an association between work in the industry and bladder cancer may record bladder cancer on the death certificate of a rubber worker in circumstances in which they would not usually record it.

\section{Cohort definition}

This study does not comprise everybody who has ever worked in the rubber industry, or even all persons who have worked in it since 1950 . It is a cohort study covering all men over 35 years of age, employed on 1 February 1967 with at least one year in that industry. All men in this cohort including those who have subsequently left the industry have been followed-up. Before suggesting how the results of the study can be extrapolated to the wider population of workers in the rubber industry the implications of our cohort definition must be considered.

Ogle (1885) described two difficulties encountered in comparisons of mortality rates between different industries. The first arose from the selection of people for work in a particular industry. He pointed out that 'a weakling will hardly adopt the trade of a blacksmith, a miner, or a railway navvy, but will preferentially take to some lighter occupation such as that of a tailor, a weaver, or a shopman' and concluded that 'it gives an unfair advantage to such industries as demand much strength or activity in those that follow them'. The second difficulty Ogle described was that resulting from less healthy people leaving the industry. Whereas the working population comprised relatively healthy people the national rates, on which the expected deaths were based, included men described as 'the broken down and the crippled who have fallen out of the ranks from all the various industries'.

Goldsmith (1975) commented that in five recent articles in the Journal of Occupational Medicine, observed mortality rates were compared with general population mortality rates. There was an inherent bias in this approach which resulted in the risk of occupational cancers being underestimated. The Figure shows that for each year of the study, except 1972 when the two SMRs were equal, the SMR for all cancers as a group has been consistently more than $15 \%$ higher than that for all deaths. The SMR for all cancers remained stable between 1968-71 and 1972-74 and that for diseases of the circulatory system showed only a marginal increase. Respiratory diseases and diseases of the digestive system both showed marked increases; the former is associated with the SMR for bronchitis and the latter with one for liver disease. It may perhaps be deduced that those whom Ogle described as 'broken down' included heavy smokers and alcoholics.

This population comprises not only men with an above average life expectancy because they are fit when they enter but it also excludes those men who have not continued to work in the industry. Many men employed in the industry before 1950 will either have left for other employment, retired, or even died before 1967. The survivors covered by this study may therefore not be representative of men employed before 1950 and can consequently not provide a guide to the role played by 'time since first exposure'. Since the leavers include those who retired through sickness and those who died, it would be reasonable to expect their mortality pattern to show greater excesses than that for men who continued in the industry.

Ogle concluded that the two effects associated with fitter people entering and subsequently continuing employment in an industry will both reduce the mortality rates for such industries as 'are in fact carried out by a body of comparatively picked men; stronger in the beginning, and maintained at a high level by the continual drafting out of those whose strength falls below the mark'. We have measured the impact of these factors on the mortality of a group of workers employed in the plastics industry (Fox and Collier, 1976). In that study it was indicated that the SMR for people who entered an industry might be reduced to below $50 \%$ of the expected during the first five years after entering. People who left within 15 years of entering the industry but were alive at the end of 15 years had a $50 \%$ higher mortality rate than those still employed in the industry at the end of that time. There will be an internal rotation of jobs as well as the movement into and out of the industry. This study takes no account of jobs performed before or after 1 February 1967. A hazard associated with particular jobs will be masked by job rotation resulting in an overall raised level but no specific groups appearing high. There may even be the tendency for older and less fit men to move into particular jobs which are not as physically demanding.

In the current state of knowledge concerning industrial and environmental carcinogenesis there is expected to be a significant period of time between initial exposure and the onset of cancer. For example, bladder cancer deaths as a result of exposures to beta-naphthylamine have occurred on average well over 20 years after initial exposure. The existence of a latent period implies that studies of men recently exposed are less meaningful than those of men exposed some time ago. Men who entered the industry as recently as 1965 and 1966 are therefore not yet expected to show signs of exposure to carcinogens.

\section{Other factors}

Other factors that may be implicated in the excess observed in this study include smoking habit and social class. In the analysis of the 1968-71 deaths it 
was suggested that the lung cancer excess in the tyre sector was greater than for the rest of the industry as a group, which itself had a significant excess compared with national rates. It was argued that it is less likely that there will be differences for smoking habit and social class between tyre sector workers and other workers in the industry than between tyre workers and the population at large.

\section{Other studies}

Mancuso (1949), Guralnick (1963), and Mancuso, Ciocco, and El-Attar (1968) have provided evidence of an excess of lung cancer in the US rubber industry. McMichael, Spirtas, and Kupper (1974) in a preliminary report on a study in the USA, almost identical in design to the present study, indicated that although the main analysis at one plant did not support the hypothesis of an excess of lung cancer, this was supported by a proportional mortality analysis of the remaining four plants. The highest SMR that was found by McMichael et al. was for cancer of the stomach (39 observed, 20.9 expected, $P<0.001)$. In a more recent analysis McMichael, Andjelkovic, and Tyroler (1976) indicated that more lung cancer cases worked on the curing processes than did controls. Mancuso (1974) in a prospective cohort study based on more than 8000 rubber workers at six plants has indicated an excess of stomach cancers primarily associated with the compounding, mill, and calender departments and the tyre and tube building department. He confirms, by comparison with other jobs in the rubber plants under study, that most lung cancers in his population are in persons who have worked in the curing departments. These studies support the findings with respect to job described in our previous report but they have not been confirmed by our present analysis. As a result of the previous report of this survey being presented to the Department of Employment's Industrial Health Advisory Committee, manufacturers agreed to support a fuller epidemiological investigation (editorial comment following Fox et al., 1974).

\section{Conclusions}

This study is general in design and provides the basis for only limited conclusions. It does however identify matters that should be followed-up and tested. The lung cancer excess throughout the industry observed from deaths occurring in 1968-71 is repeated in 1972-74; this was statistically significant in the tyre sector but was apparent in other sectors of the industry.

The information recorded on job is inadequate for detailed analysis. The investigation could be enhanced by the inclusion of a retrospective study concentrating on occupational histories of a sample of men who died of lung cancer and comparing them with those of suitable controls such as was done by McMichael et al. (1974). It should be emphasized that we do not even know whether the men who died from bladder cancer in this study had previously been exposed to the recognized carcinogens. All these men in group $\mathrm{C}$ had previously been employed with a different firm and therefore some of them might have been exposed to these chemicals. It is however unlikely that they are the prime reason for the sudden increase in bladder cancer deaths. The occupational histories for the bladder cancer cases should be sought in a similar study as those for lung cancer. The indication that in the United States of America there are more cases of stomach cancer among rubber workers should merit attention in the United Kingdom.

This study indicates there is a need to set up a search for possible causes for these excesses. Only weak evidence has so far been provided on the processes involved. In the absence of particular chemicals being isolated it is prudent to recommend that greater attention be paid to the overall environment in the industry to reduce all exposure to potential hazards to a minimum.

The principal architect of this study was Dr R. Owen who with Dr G. B. Hill, who prepared the survey for computer analysis, takes most of the credit for the speed with which up-to-date analyses can be produced. $\mathrm{Mr}$ R. V. Hayball has been responsible throughout the course of the survey for the organization and routine processing of details relating to death and cancer notifications received from the Office of Population Censuses and Surveys for England and Wales and the Registrar General for Scotland.

\section{References}

Case, R. A. M. and Hosker, M. E. (1954). Tumour of the urinary bladder as an occupational disease in the rubber industry in England and Wales. British Journal of Preventive and Social Medicine, 8, 39-50.

—, McDonald, D. B., and Pearson, J. T. (1954). Tumours of the urinary bladder in workmen engaged in the manufacture and use of certain dyestuff intermediates in the British chemical industry. Part I. The role of aniline, benzidine, alphanaphthylamine. British Journal of Industrial Medicine, 11, 75-104.

Fox, A. J. and Collier, P. F. (1976). Low mortality rates in industrial cohort studies due to selection for work and survival in the industry. British Journal of Preventive and Social Medicine, 30, 225-230.

—, Lindars, D. C., and Owen, R. (1974). A survey of occupational cancer in the rubber and cablemaking industries: results of five year analysis 1967-1971. British Journal of Industrial Medicine, 31, 140-151.

Goldsmith, J. R. (1975). What do we expect from an occupational cohort? Journal of Occupational Medicine, 17, 126-131.

Guralnick, J (1963). Mortality in 1950 by Occupation and 
Industry, Vital Statistics-Special Reports, 53, 1-5, June 1961-September 1963. US Department of Health, Education, and Welfare, Washington, DC.

McMichael, A. J., Andjelkovic, D. A., and Tyroler, H. A. (1976). Cancer mortality among rubber workers. Annals of the New York Academy of Sciences, 271, 125-137.

_-, Spirtas, R., and Kupper, L. L. (1974). An epidemiologic study of mortality within a cohort of rubber workers 1964-72. Journal of Occupational Medicine, 16, 458-464.

Mancuso, T. F. (1949). Occupational cancer survey in Ohio. In Proceedings of the Public Health Cancer Association of America, pp. 56-70.

- (1974). Epidemiological investigation of occupational cancers in the rubber industry. In Proceedings of the International Conference on Occupational Cancers and Health Hazards in the Chemical and Rubber Industry, Geneva, October 1974.

- Ciocco, A., and El-Attar, A. A. (1968). An epidemiologic approach to the rubber industry-A study based on departmental experience. Journal of Occupational Medicine, 10, 213-232.

- - and El-Attar, A. A. (1966). Dynamic changes in industrial cohort studies. Industrial Medicine and
Surgery, 35, 1059-1067.

Minister of Labour (1967). The Carcinogenic Substances Regulations, 1967. Cmd. 879. HMSO, London.

Minister of Pensions and National Insurance (1953). The National Insurance (Industrial Injuries) (Prescribed Diseases) Regulations, 1953, Amendment No. 2. Cmd. 1740. HMSO, London.

Ogle, W. (1885). Letter to the Registrar General on the Mortality in the Registration Districts of England and Wales during the ten years 1871-80. Forty-fifth Annual Report of the Registrar General of Births, Deaths and Marriages in England-Supplement 1871-1880, Part 1, p. xxiii. Eyre \& Spottiswoode, London.

Registrar General (1972). Statistical Review of England and Wales for the two years 1966-67-Supplement on Cancer. HMSO, London.

Registrar General (1967-73). Statistical Reviews of England and Wales: Part 1, Tables, Medical. HMSO, London.

World Health Organization (1967). International Classifcation of Diseases. WHO, Geneva.

Received for publication 30 March 1976.

Accepted for publication 16 June 1976. 